\title{
Orientação Sexual e Homofobia na Série Televisiva Glee
}

\author{
Micaela Leite Santos Montezuma de Carvalho ${ }^{1}$ \\ Filomena Teixeira ${ }^{2}$
}

\begin{abstract}
RESUMO
O projeto que se apresenta pretendeu contribuir para a construção de conhecimentos que apelassem a uma melhor compreensão da violência e da discriminação homofóbicas e perceber as perspectivas dos/as alunos/as relativamente às mensagens discriminatórias e estereotipadas veiculadas pela série televisiva Glee. A intervenção, realizada no âmbito do Mestrado em Educação para a Saúde, envolveu uma turma de $9^{\circ}$ ano de escolaridade, constituída por 19 alunos/as. A opção pela metodologia de projeto permitiu-nos sensibilizar os/as estudantes para a necessidade do reconhecimento das diferentes orientações sexuais, tendo ainda possibilitado, a reflexão acerca das manifestações de violência, preconceito e discriminação de que são alvo as pessoas que assumem identidades não heterossexuais.
\end{abstract}

PALAVRAS-CHAVE: Violência. Discriminação homofóbica. Série televisiva. Educação.

\section{Sexual Orientation and Homophobia in the TV Series Glee}

\begin{abstract}
The present project aimed to contribute for construction of knowledge that would appeal to a better understanding of homophobic violence and discrimination and to perceive students' perspectives on the discriminatory and stereotyped messages conveyed by the television series Glee. The intervention carried out within the scope of the master's in health education, involved a class of 9th year of schooling, made up of
\end{abstract}

\footnotetext{
${ }^{1}$ Mestre em Educação para a Saúde. Escola superior de Educação. Instituto Politécnico de Coimbra, Portugal. Email:micaelamontezuma@gmail.com.

${ }^{2}$ Doutora em Didática. Escola Superior de Educação do Instituto Politécnico de Coimbra; Centro de Investigação Didática e Tecnologia na Formação de Formadores da Universidade de Aveiro.
} 
19 students. The option of the project methodology allowed us to sensitize the students to the need to recognize the different sexual orientations and made possible the reflection about the manifestations of violence, prejudice and discrimination that target people who assume nonheterosexual identities.

KEYWORDS: Violence. Homophobic discrimination. Série televisiva. Education.

\section{Introdução}

Desde meados do século XX, têm sido constantes as lutas pela igualdade de direitos humanos e liberdades fundamentais das pessoas não subsumíveis aos padrões dominantes do exercício da sexualidade e afetividade. Embora a nossa sociedade pareça, cada vez mais preocupada com os quadros de opressão e desigualdades vivenciados pelos/as jovens e adultos/as LGBT, ainda há muitos desafios e problemas a serem defrontados quando refletimos sobre este tema.

A escola constitui uma parte integrante das histórias pessoais. Edificada em pilares heteronormativos, a escola veicula valores, crenças e reproduz as noções tradicionais sobre sexualidade e papéis que convencionalmente são atribuídos aos géneros. Porém, este carácter estruturante do preconceito e do estereótipo, deixa uma pesada herança aos indivíduos que destabilizam os postulados heteronormativos. Fruto da intolerância e da discriminação homofóbica, a estes sujeitos é-lhes atribuído um lugar marginal e silencioso e uma sexualidade "desviante" e "anormal" (Borrillo, 2009).

Desde 2009, a lei portuguesa prevê o caráter obrigatório da educação sexual nos projetos educativos dos agrupamentos de escolas. Porém, as questões relacionadas com a diversidade de orientações sexuais e a 
pluralidade de identidades de género continuam remetidas ao silêncio curricular.

Consideramos que a compreensão e o conhecimento relativos às questões relacionadas com a orientação sexual contribui para reduzir os padrões heterossexistas e a visão normativa estigmatizante e discriminatória relativa à vivência da sexualidade e do género (Nogueira \& Oliveira, 2010). Assim, procurando enfrentar novos desafios educativos, desenvolvemos o trabalho de projeto que agora se apresenta, no âmbito do Mestrado em Educação para a Saúde (Montezuma, 2012). Este projeto visou sensibilizar os/as alunos/as para as diferentes orientações sexuais e possibilitou a reflexão sobre a violência homofóbica exercida contra pessoas que assumem identidades não heterossexuais.

A importância dos media na vida dos/as jovens e a influência que sobre eles é exercida expondo-os/as às suas representações, levou-nos a considerar a utilização da série televisiva Glee, enquanto instrumento pedagógico, de relevante importância, possibilitando a desconstrução de posições préconcebidas. Assente nos elementos da estética camp e da performatividade queer, Glee destaca a visão da "diferença" como padrão de construção social (Dominguez, 2010). Tendo em conta que os métodos educativos mais efetivos para ensinar sobre sexualidade, género, igualdade e direitos humanos são os participativos e centrados no/a estudante, elaboraram-se, assim, diversas ferramentas pedagógicas por forma a munir os/as jovens de meios que lhes permitam analisar criticamente os valores veiculados por esta série televisiva (Teixeira, 2010).

\section{Desenvolvimento}

O projeto que se apresenta, de natureza qualitativa e cariz exploratório, foi desenvolvido em Coimbra, numa turma do $9^{\circ}$ ano de escolaridade constituída por dezenove alunos/as, dos quais doze eram raparigas e sete eram rapazes. A idade dos/as alunos/as compreendia os 13 e os 15 anos. 
Os instrumentos pedagógicos que serviram de base a este projeto, foram idealizados e elaborados de acordo com os objetivos do estudo e as características da turma. Dividiram-se em dois grupos: instrumentos de recolha de dados e recursos multimédia.

Nos instrumentos de recolha de dados incluem-se as três fichas de análise da série televisiva Glee, elaboradas exclusivamente para o presente projeto, e que tiveram por base os trabalhos desenvolvidos por Diéz Gutiérrez (2004), Carmo e Ferreira (1998), Domínguez (2010), Junqueira (2009a; 2009b). Dos recursos multimédia fazem parte um PowerPoint sobre "Orientação Sexual e Homofobia”, elaborado com base na revisão do estado da arte, e que serviu de suporte à exploração, em sala de aula, da temática em questão. Constam ainda destes recursos as cenas da série Glee objeto de análise.

A análise das respostas obtidas das três fichas (Theatricality preenchida individualmente, Duets - preenchida em grupo e Never been kissed - preenchida individualmente), cuja descrição pormenorizada será aqui apresentada, permitiu aferir as formas de pensar, de sentir e as atitudes dos/as alunos/as quanto às situações de discriminação, preconceitos e estereótipos face à orientação sexual veiculadas nas cenas de Glee. Sempre que possível estabeleceu-se ponte entre os resultados obtidos e a fundamentação teórica que serviu de base a este estudo.

\section{Theatricality}

Desta cena fazem parte três personagens, Kurt, gay assumido, Finn, heterossexual e colega de Kurt no clube Glee e Burt, pai de Kurt. Na tentativa de fazer as pazes com Finn, Kurt decora o quarto que ambos vão partilhar depois do casamento dos seus pais (a mãe de Finn e o pai de Kurt). Finn argumenta que não se quer vestir à frente de Kurt, nem tão pouco quer aquela decoração, uma vez que sabe que Kurt está apaixonado por ele. Irritado, Kurt afirma que é apenas um quarto e que se Finn o pretender podem voltar a decorá-lo. Finn, de forma cruel, afirma que, nesse caso, as 
primeiras coisas a tirar seriam o candeeiro e o cobertor "amaricados". Burt (pai de Kurt) ouve Finn e questiona se ele também usa a palavra "preto" e "atrasado mental" para insultar pessoas em função da raça ou de deficiência física. Finn tenta defender-se mas Burt, assumindo que o achava incapaz de tais atitudes, pede-lhe para sair de casa.

Relativamente ao género, salienta-se o facto de alguns/umas alunos/as $(\mathrm{N}=8)$ considerarem que a personagem Kurt revela normas de comportamento e de aparência estereotipicamente femininos. Todos os/as alunos/as (N=19) são unânimes em considerar que a personagem Finn assume um papel característico do género masculino. Quando questionados sobre o porquê da sua opção, constatou-se que todos os alunos $(\mathrm{N}=7)$ e uma aluna perpetuam o julgamento estereotípico no qual todos gays são percebidos como femininos, indicado em expressões como "O Kurt é gay por isso é feminino (...)" (M7), "Kurt (...) gosta de coisas femininas e age como tal. Finn é masculino, gosta de raparigas e age como homem (...)" (F1) ou “(...) o Kurt é gay e o Finn parece normal” (M3). Estes resultados são consistentes com as teorizações que defendem que a homossexualidade é pensada de forma estereotipada, reconhecendo na figura do gay atitudes, gestos e comportamentos femininos ou efeminados. De facto, à luz dos estereótipos as lésbicas são vistas como mais masculinas que as mulheres heterossexuais e os gays como mais femininos que os homens heterossexuais. Nesta perspetiva, o homem heterossexual, constrói a sua masculinidade procurando a diferenciação do feminino, ou seja, as masculinidades hegemónicas assentam no desprezo e na inferiorização em relação a tudo aquilo que possa parecer feminino. O cúmulo da falta de virilidade consiste na aproximação à feminilidade (Borrillo, 2009). Também o discurso de um aluno, referindo-se à "normalidade" de Finn, é exímio a revelar a hierarquização das sexualidades. A heterossexualidade assume uma posição superior e é tida como a única forma "natural" e "normal" de sexualidade, relegando para o desvio, para a anormalidade e perversão 
homens e mulheres homossexuais e bissexuais (Weeks, 2000; Vale de Almeida, 2004; Louro, 2000b).

Já no que diz respeito às características dos personagens serem idênticas às das pessoas com que os/as alunos/as normalmente convivem, os resultados foram muito semelhantes: dez alunos/as consideram que são idênticas e nove alunos/as reconhecem que os personagens em nada são semelhantes às pessoas com quem têm algum tipo de relacionamento.

Quando se colocou a questão: Como interpretas a reação de Finn quando diz: Eu não posso viver aqui. Sou um gajo, a maioria dos/as alunos/as ( $N=10)$ salienta o facto do Finn adotar uma postura preconceituosa “(...) ele [Finn] acha que o quarto é mais feminino e como não lida bem com a homossexualidade tem uma atitude mais preconceituosa" (F3). Os relatos de duas alunas são bastante claros no que se refere ao preconceito vivenciado pelos homossexuais “(...) ele [Finn] pode estar com medo daquilo que outras pessoas vão pensar quando souberem que ele dorme no mesmo quarto que um rapaz homossexual" (F5) e "Por um lado acho que ele está a ser injusto mas por outro lado acho que tem razão, pois deve ser complicado dormir no mesmo quarto de um homossexual." (F4). Para um aluno, o Finn tem "Uma reação à homem" (M6). Segundo Borrillo (2009), os elementos modeladores do "jeito de ser homem" são a competição, o medo da fraqueza, o controlo dos sentimentos e a homofobia. Ser homem significa ser rude, competitivo, olhar as mulheres com superioridade e detestar os homossexuais.

Pretendeu-se ainda averiguar se os/as alunos/as acreditavam que a situação visualizada ocorreria da mesma forma se o Kurt fosse heterossexual. A maioria dos/as alunos/as $(\mathrm{N}=15)$ considera que a personagem Finn não recusaria partilhar o quarto com o Kurt, se ele fosse heterossexual. Pelo trecho abaixo podemos dar-nos conta do mito existente sobre a promiscuidade dos/as homossexuais "Acho que não pois iria [Finn] sentir-se mais à vontade, sabendo que todas as vezes que tomasse banho não teria receio de o meio-irmão o ver sem roupa"(F3). Estes relatos remetem 
para a estereotipia de homossexuais promíscuos, depravados, pedófilos (Leal, 2004), frívolos e solitários, incapazes de estabelecer relações amorosas duradouras, e de preservar uma vida afetiva plena. Já as lésbicas são percebidas como hostis e agressivas com os homens (Costa, Oliveira \& Nogueira, 2010; Rodrigues, Nogueira \& Oliveira, 2010; Borrillo, 2009). Na mesma linha de pensamento, sujeita-se o homossexual ao papel de pervertido, do outro, do estranho e do diferente e criam-se resistências a assumir qualquer tipo de identificação com os sujeitos homossexuais: "Não, porque assim já não havia motivos para outros pensarem que por dormir num quarto com um rapaz homossexual também ele era homossexual"(F5). A homossexualidade é vista como "contagiosa" e os homossexuais são percebidos como uma ameaça à coesão cultural e moral da sociedade, como tal, a aproximação a este grupo estigmatizado pode ser interpretada como uma adesão a tal prática ou identidade (Louro, 2000a; Borrillo, 2009).

$\mathrm{Na}$ questão seguinte tentou perceber-se a reação dos/as alunos/as ao discurso de Burt. As questões da igualdade e da discriminação estão muito presentes em alguns discursos:“(...) Burt pretende mostrar que todos somos iguais independentemente das doenças, etnias, religiões, forma de agir, escolhas, gostos, orientações sexuais”(F5), ou “(...) ser homossexual é igual, é uma pessoa igual às outras, que não há diferença”. Porém, na realidade, aos homossexuais é destinado um tratamento diferente do experimentado pelos que não transgridem a norma heterossexual. Os/as homossexuais são vítimas diárias do preconceito e da discriminação. Esta discriminação, consequência da homofobia, envolve distinção, e exclusão que são prejudiciais "ao reconhecimento, ao gozo ou ao exercício em pé de igualdade de direitos humanos e liberdades fundamentais" (Rios, 2009, p. 71). A lógica discriminatória alimenta-se da necessidade de tratar os/as homossexuais como inferiores. Numa sociedade em que identidade heterossexual é imposta, persistem as ideias que atribuem à homossexualidade um caráter patológico, aos/às homossexuais é cunhada a libertinagem sexual e a 
incapacidade afetiva e insiste-se na procura incessante de uma causa para a homossexualidade.

Seguidamente, solicitámos aos/às alunos/as que identificassem os momentos na cena que consideravam reprováveis. Uma vez que o preenchimento desta ficha de análise ocorreu antes da desconstrução da temática, por parte da formadora, optou-se por utilizar a expressão "comportamentos reprováveis" em vez de "comportamentos homofóbicos". Alguns alunos e algumas alunas $(\mathrm{N}=9)$ identificam como comportamento reprovável a utilização da palavra "amaricado": "Quando Finn diz que o candeeiro e o cobertor são amaricados" (M3), ou "Quando Finn agride verbalmente Kurt” (F10). Outros/as consideraram reprovável o facto de Finn não querer partilhar o quarto com Kurt "Quando o Finn diz que não pode viver num lugar onde vive um homossexual" (F3). Por sua vez, uma aluna (F6) comenta: " A discussão entre Kurt e Finn porque mostra como é a vida da maior parte dos homossexuais, na vida real" o que nos leva a refletir sobre a discriminação, o desprezo e a opressão a que estão sujeitos inúmeros/as jovens e adultos/as LGBT. Não obstante, um aluno considera como reprovável "Quando Kurt se atira a Finn" (M5). Algumas destas narrativas vão ao encontro do que a literatura nacional e internacional tem vindo a discutir sobre as formas de violência física e não-física que incidem sobre jovens e adultos/as LGBT. De facto, o conceito de homofobia surge muito associado ao de violência. Enquanto a violência física se torna mais brutal e visível, uma vez que atinge a integridade corporal dos sujeitos, a violência não-física, expressa-se sob a forma do não-reconhecimento e do insulto, igualmente penosos e nocivos (Rios, 2009). Conforme observa Sullivan (1996, citado por Junqueira, 2009b, p. 17), desde cedo, as pessoas LGBT confrontam-se com a "pedagogia do insulto", constituída por piadas, jogos, insinuações, apelidos e expressões que desqualificam e desvalorizam. Importa ainda aduzir as conclusões do estudo de Oliveira, Pereira, Costa e Nogueira (2010) Pessoas LGBT - identidades e discriminação. Num levantamento entre mais de 900 homens e mulheres homossexuais, 
bissexuais, queer e pansexuais constatou-se que os/as inquiridos/as foram vítimas de insulto, em função da sua identidade sexual, três ou mais vezes. Os autores concluem, por isso, que em Portugal o insulto é usado como forma de estigmatização das pessoas LGBT, assumindo um caráter banalizado e frequente.

Por fim, onze alunos/as consideram que a cena poderia influenciar a aceitação, por parte dos/as jovens, das diferentes orientações sexuais e oito alunos/as julgam que a cena não exerce qualquer tipo de influência. Um aluno (M7) acredita que a cena não exerce qualquer influência "Porque os jovens já têm opiniões formadas" e uma aluna reforça esta opinião "Porque as pessoas não são capazes de mudar" (F9). Existem, no entanto, opiniões contrárias. Assim nos relata uma aluna "Com esta cena é provável que eles [jovens] percebam que ser-se homossexual é perfeitamente normal, não é nenhuma doença nem é contagioso. São pessoas como as outras...” (F5) outra aluna acredita que a cena pode influenciar negativamente a aceitação da homossexualidade "Porque os jovens já sem verem isto são preconceituosos então com isto ainda são piores" (F4).

Este projeto tem-nos possibilitado a reflexão sobre a influência dos media no desenvolvimento da sexualidade dos/as adolescentes e o estabelecimento, ao mesmo tempo, de uma articulação com o processo pedagógico. No bojo deste debate necessário, emerge a comunidade científica apontando os media como o fator modelador de comportamentos e de atitudes, influenciando a tomada de decisão da maioria dos/as adolescentes. É, por isso, importante desenvolver estratégias didáticas com a finalidade de desconstruir as mensagens de sexualidade e de género veiculadas nos programas dirigidos a este tipo de público, de forma a contribuir não só para a sua consciencialização mas também para a sua análise crítica e reflexiva (Folhas, Pessoa \& Teixeira, 2010).

\section{Duets}


Desta cena fazem parte duas personagens: Finn e Sam, ambos heterossexuais e colegas de Kurt no Clube Glee. Quando Will Schuester (professor de espanhol que dirige o Clube Glee) propõe que se fizessem duetos no Clube Glee, Kurt escolhe imediatamente Sam para seu par. Sam concorda, porém Finn tenta demovê-lo de fazer o dueto com Kurt. Finn alega que seria o mesmo que assinar uma "sentença de morte", pois iria ser atormentado por todos/as os/as colegas da escola. Quando Sam pergunta se Finn tem "problemas" com gays, Finn nega mas afirma que todos/as os/as outros/as têm. E como vivem no mundo deles/as têm que seguir as suas regras. A cena acaba com Sam a sair do balneário masculino e a ser surpreendido por alguns membros da equipa de futebol americano que lhe despejam sumo de tomate para cima.

No que toca ao género, todos os grupos (G1 a G5) são unânimes em considerar que ambos os personagens refletem as normas de comportamento e aparência estereotípicas do género masculino. Para os diferentes grupos, "são os dois do sexo masculino, mesmo que fossem homossexuais continuavam a ser homens" (G1), "são ambos masculinos, porque têm genes masculinos" (G2), "os dois têm atributos masculinos" (G3), “(...) são ambos heterossexuais" (G4) e "porque são ambos rapazes" (G5). Por estes discursos, percebemos a dinâmica do processo cultural que reforça o preceito de que o ser humano enquanto macho ou fêmea, e cuja essência se encontra fixada nos cromossomas e nas hormonas, é possuidor de um sexo (genitalizado) que atrela o desejo sexual a um dos dois géneros possíveis - feminino e masculino (Louro, 2009; Sousa Filho, 2009). Esta lógica linear sexo-génerodesejo subverte tudo aquilo que é defendido pelos teóricos queer, nomeadamente Judith Butler que foge da relação intrínseca entre sexo, género e sexualidade. Para a filósofa, o género não é natural, não havendo relação entre o corpo que se tem e o género. O género é antes uma ficção cultural, o efeito performativo de atos reiterativos (Vale de Almeida, 2004), sendo os homens e as mulheres fruto do discurso que formatam os seus corpos. 
Pelas respostas à questão seguinte compreendemos que, ao contrário do que aconteceu na ficha Theatricallity, todos os grupos (G1 a G5) consideram que os personagens da cena Duets têm características semelhantes às das pessoas com quem têm proximidade. Dado que os dois personagens desta cena são heterossexuais, e um dos personagens da cena Theatricallity é homossexual (Kurt), acreditamos que estes resultados vão ao encontro do "princípio da heterossexualidade presumida" que postula que não existem homossexuais em determinados ambientes. No caso de existirem, deverá ser uma "coisa passageira", que "se resolverá quando ele/ela encontrar a pessoa certa" (Becker, 2005 citado por Junqueira, 2009a, p. 31).

Quando questionados, os diferentes grupos reconhecem que a opinião "dos outros" - que entendemos aqui como os/as amigos/as, a família e a comunidade - é o que fomenta a atitude de Finn "se fizesse um dueto com Kurt irão ser gozados pelos homofóbicos” (G3) ou “(...) Finn preocupa-se demais com o que as pessoas dizem"(G4).

Quando questionados sobre a possibilidade de Finn reagir de forma diferente se Kurt fosse heterossexual, todos os grupos (G1 a G5) afirmam que sim. O estigma e desvalorização que se instalam em torno das identidades não-heterossexuais voltam a estar patentes nas diferentes respostas: "porque se o Kurt tivesse uma orientação sexual diferente as pessoas iam vê-lo com outros olhos" (G2) ou “(...) se Kurt não fosse homossexual, não estragava a reputação de Finn" (G5).

Ainda quatro grupos (G2, G3, G4 e G5) consideram que Finn não tinha razão em afirmar que fazer um dueto com um homossexual é uma "sentença de morte". E justificam: "Kurt é uma pessoa normal(...)" (G2), "porque fazer um dueto com um homossexual é como fazer com um heterossexual" (G3). Contrariamente um grupo (G1) sublinha que "naquela escola os alunos adotam uma mentalidade menos avançada e iriam fazer-lhe a vida negra".

No que respeita aos momentos na cena que consideravam reprováveis, apenas três grupos (G1, G2 e G3) referem como reprovável o facto de Finn 
assumir que fazer um dueto com um homossexual é uma sentença de morte. Estas ideias estão presentes em trechos como "Finn diz que cantar com um homossexual não o deixará tornar-se popular (...) e fazer um dueto com Kurt é uma sentença de morte" (G1). No entanto, dois grupos (G4 e G5) identificam unicamente como atitude reprovável "quando atiram o sumo ao Sam" (G4). O facto destes dois últimos grupos não atribuírem ao discurso preconceituoso e discriminatório da personagem Finn um cariz reprovável, denuncia, uma vez mais, o ostracismo social, a indiferença e a invisibilidade a que gays e lésbicas estão sujeitos/as. Esta negação do valor, de um modo de ser ou de viver, cria as condições necessárias ao tratamento indiferente, degradante e insultuoso (Rios, 2009).

$\mathrm{Na}$ continuação da análise sobre influência das mensagens veiculadas pelos media na socialização dos/as jovens, questionámos novamente os/as alunos/as sobre a forma como a cena visualizada poderia influenciar a aceitação das diferentes orientações sexuais. Os cinco grupos consideram que a cena pode influenciar a aceitação das diferentes identidades sexuais e argumentam "sim, pois os rapazes, principalmente, são influenciados por outros que normalmente são homofóbicos" (G3), "há pessoas que não acreditam em si mesmas e que agem influenciadas"(G2) e "porque a televisão influencia muito os jovens nos dias de hoje" (G1).

\section{Never been kissed}

Desta cena fazem parte dois personagens: Kurt e Karofsky que são colegas na mesma escola. Kurt é gay assumido e aceita perfeitamente a sua sexualidade. Karofsky assume-se como heterossexual e resiste à sua própria identificação como gay. Karofsy, o homofóbico jogador de futebol americano, empurra Kurt contra os cacifos do corredor da escola. Kurt, farto de ser uma vítima nas suas mãos, corre atrás dele até aos balneários onde iniciam uma discussão. E Kurt grita: "o pesadelo de todos os heterossexuais é que, nós gays, queremos converter-vos. Pois adivinha, pernil de porco, tu não és o meu tipo.” E ao mesmo tempo que Kurt afirma que Karofsky é um infeliz e 
por mais que o agrida ele nunca deixará de ser gay, Karofsky ameaça baterlhe. Porém, o inesperado acontece e em vez de o agredir, Karofsky beija Kurt.

Quando solicitámos aos/às alunos/as que revelassem as emoções, sentimentos, ideias, etc. que a cena Never been kissed lhes provocou, constatou-se que o discurso da heteronormatividade, dos valores negativos face à homossexualidade e da rejeição parecem estar muito presentes em alguns discursos (N=9): “enjoos” (M1), “nojo” (M2),"é a parte quando eles se beijam, porque é nojento" (M4), “provoca-me nojo, agonia e enjoos” (M7), "provoca-me uma coisa esquisita, porque eu não sou contra a homossexualidade mas não gosto de ver estas coisas" (F10), "choque" (F11). Não por acaso, DiPlacido (1998, citado por Pereira \& Leal, 2004, p. 246) nota que a nossa sociedade heterossexista apenas tolera os gays, as lésbicas e os bissexuais se não se assumirem e permanecerem para sempre 'no armário'. Contudo, algumas alunas $(\mathrm{N}=5)$ mencionam o conflito interior vivido por Karofsky, que, reconhecendo o seu sentimento de atração por alguém do mesmo sexo - Kurt -, inicia "um processo psicológico de autorrotulação que não é acompanhado por nenhuma abertura interpessoal das suas próprias emoções e comportamentos” (Pereira \& Leal, 2004, p. 246). “(..) Karofsky agride o Kurt, pois tem medo de se assumir como ele” (F2), “(..) acho pena por o Karofsky se tenta esconder por de trás do que realmente sente" (F3). Uma aluna utiliza mesmo a expressão "homofobia internalizada" para enfatizar a sensação de vergonha de Karofsky face à perspetiva de ser identificado como gay, "Eu adoro esta cena, pois o Karofsky é muito mau e odeia gays mas no fundo não passa de um homofóbico internalizado que não consegue viver com o facto de gostar de rapazes" (F9).

Para Ilan Meyer e Laura Dean (1998, citado por Pereira \& Leal, 2004, p. 246) a homofobia internalizada é o "direcionamento das atitudes sociais e negativas para o self da pessoa gay, levando à desvalorização desse self e resultantes conflitos internos e uma autoimagem empobrecida”. Estes sujeitos assumem como "defeito" a sua homossexualidade e, como tal, evitam 
a exposição pública e contêm-se na expressão dos seus sentimentos e comportamentos (Pereira \& Leal, 2004).

Relativamente a Kurt, praticamente todos os/as alunos/as ( $=18)$ consideram que a característica que mais se destaca neste personagem é o facto de ser uma "vítima" nas mãos de Karofsky.

Em relação ao género, deve realçar-se que a maioria dos/as alunos/as $(\mathrm{N}=17)$ percebe, uma vez mais, Kurt como feminino e alguns/umas alunos/as $(\mathrm{N}=4)$ consideram que Karofsky assenta também no mesmo género. "São os dois gays" (M2), "Kurt apesar de ser do sexo masculino, por vezes comportase como uma pessoa do sexo feminino" (F2). É notório, mais uma vez, nestes discursos que, à semelhança do que Louro (2009) destacou, a transgressão da norma heterossexual é representada como uma "perda" do género "original”. Ainda relativamente a Karofsky, dezassete alunos/as consideram que não representa o estereótipo de um homossexual e dois alunos/as consideram que sim. E as narrativas dos/as alunos/as sustentam novamente as crenças e normas associadas às imagens estereotipadas do gay feminino e do "macho" heterossexual, forte, corajoso, agressivo e não efeminado: "porque faz tudo como um heterossexual”(M5), “(...)porque ele tem atitudes masculinas(...)"(F1), "porque tem um comportamento de macho" (F2), "porque foi agressivo (...)"(M2),"porque tem uma postura muito masculina diferente do que se diz dos homossexuais”(F3), “(...) tem um ar forte mas é homossexual"(F6), "porque tem um comportamento de homem"(F7), "porque não tem tiques nem se veste afeminado nem dá a parecer sequer que é homossexual"(F9).

Quisemos ainda perceber se os/as alunos/as identificam como preconceituoso o comportamento de Karofsky. Os resultados quase unânimes (dezoito alunos/as consideram que sim e apenas um aluno considera que não) evidenciam uma homogeneidade discursiva: "porque só pelo Kurt ser gay pensa que ele é má pessoa"(M5), "porque embora seja gay não o aceita e esconde-se por de trás duma personagem forte e fria"(F3), 
"porque não queria conviver com Kurt e muito menos admitir que também era homossexual"(F5).

Quando questionámos aos/às alunos/as se concordavam com a afirmação de Kurt "o pesadelo de todos os heterossexuais é que, nós gays, queremos converter-vos", onze alunos/as responderam que não e oito acreditam que sim. Existe alguma variabilidade no discurso por parte dos/as alunos/as. Alguns discursos remetem-nos para dimensão da homossexualidade enquanto tendência perversa e contagiosa e para o homossexual enquanto predador impiedoso: "porque os gays querem que o mundo seja todo gay"(M3), "porque quando estamos perto de gays temos medo das atitudes que eles podem ter" (M4), "muitas pessoas heterossexuais têm medo de se tornarem gays" (F8). Contrariamente outros discursos valorizam a igualdade de direitos reivindicados pelos indivíduos LGBT e a homossexualidade enquanto variante natural da expressão da atracão sexual e/ou envolvimento emocional ou amoroso (APA, 2008 citado por Nogueira \& Oliveira, 2010). "Porque a vontade dos gays não é converter os heterossexuais mas sim serem felizes e defenderem os seus direitos"(F3), "porque a homossexualidade não é contagiosa(...)”(F2) e "Normalmente há, por parte dos heterossexuais, um medo em relação aos homossexuais os poderem converter mas isso é impossível uma vez que cada um nasce já com a sua orientação sexual bem definida"(F5). Neste relato torna-se evidente a construção estanque da identidade, isto é o facto de indivíduos homossexuais e heterossexuais se assumirem de forma clara e consistente, toda a vida. Estes discursos fazem, mais uma vez, tábua rasa às perspetivas queer, que justificam o facto de algumas pessoas acordarem "um dia para uma realidade de orientação sexual diferente daquela que sempre acreditaram ser a sua" (Leal, 2004, p. 233).

Todos/as os/as alunos/as (N=19) concluem também que Karofsky não lida bem com a sua orientação sexual. O "medo" da própria homossexualidade e a interiorização de valores negativos face à homossexualidade continuam muito presente nas narrativas dos/as 
alunos/as: "ele quer esconder a sua orientação sexual”(M1), "tem medo"(F4), "Karofsky não quer aceitar que é homossexual e por esse motivo tenta esconder isso do mundo através da atitude de machão e violento” (F5), “(...) ele é homossexual mas não o aceita"(F9) e "tem fobia a gays (...) não quer ser gay" (F11). Esta visão é corroborada por Pereira e Leal (2004) quando afirmam que os homens que resistem à própria identificação como gays internalizam o homonegativismo e uma série de estereótipos, que resultam do facto de viverem numa sociedade que discrimina a sua natureza.

Relativamente aos comportamentos homofóbicos veiculados na cena, a maioria dos/as alunos/as $(\mathrm{N}=15)$ identifica a agressão física vivenciada por Kurt como um comportamento manifestamente homofóbico. Outros/as assinalam a discussão entre Kurt e Karofsky no balneário e algumas alunas revelam também que o facto de Karofsky sugerir que Kurt deveria frequentar o balneário feminino é um ato de discriminação de caráter homofóbico: "quando Karofsky agride violentamente Kurt no corredor”(F5), "quando o Karofsky o empurra [Kurt] e o agride verbalmente" (F9), "quando Karofsky empurra Kurt e quando lhe diz para ir para ir para o balneário das meninas" (F11).

Ao serem novamente indagados sobre a influência da cena visualizada na aceitação das diferentes orientações sexuais, os/as alunos/as relatam que a cena "demonstra que não há problema em assumir as orientações sexuais de cada um"(F3), "hoje em dia as pessoas levam a TV muito a sério"(F11), "mostra como a vida é na realidade" (F8), "podem-se ver no papel dos gays e ver o que sofrem"(F12), porém um aluno acrescenta também que "depende das mentalidades de cada um e da educação com que foram criados"(M4).

\section{Conclusão}

Os resultados obtidos neste estudo encontram acolhimento nos diversos estudos nacionais e internacionais. Em relação aos estereótipos, os resultados corroboram os dados encontrados na literatura, visto que os 
homossexuais são frequentemente identificados como femininos e frágeis e os heterossexuais são retratados como fortes e confiantes. Os alunos/as identificam a resistência em assumir identificações com os sujeitos homossexuais e a violência física e verbal, como as formas mais representativas de discriminação e homofobia retratadas nas cenas visualizadas. Estes discursos são, assim, congruentes com outras investigações que defendem que a heterossexualidade é tida como a única forma natural e "normal" de sexualidade, denunciando a indiferença, invisibilidade e a violência a que homens e mulheres homossexuais estão sujeitos (Rios, 2009; Weeks, 2000). Ainda concordantes com outras investigações, são os resultados obtidos sobre a influência dos media na socialização dos/as adolescentes. A maioria dos/as alunos/as considera que as cenas visualizadas podem influenciar a aceitação, pelos/as jovens, das diferentes orientações sexuais. Podemos, assim, concluir que a série Glee, utilizada como instrumento pedagógico, contribuiu para a reflexão efetiva sobre as questões do preconceito, discriminação e homofobia contra quem transgride a norma heterossexual. Porém, convém salientar que continua a prevalecer, em alguns e algumas estudantes, o discurso do preconceito e da estigmatização em relação aos sujeitos homossexuais. Estes resultados poderão estar relacionados com as limitações deste estudo, que se prendem fundamentalmente com o tempo disponível para o desenvolvimento e implementação do projeto. Desta forma, torna-se evidente a necessidade de continuar, no futuro, o desenvolvimento de ações educativas que permitam repensar e desconstruir os preconceitos, instituídos culturalmente, sobre as representações atribuídas à diversidade do desejo sexual e às diferentes identidades de género.

\section{Referências}

BORRILlO, D. A homofobia. In Lionço, T. \& Diniz, D. (Orgs). Homofobia \& Educação: um desafio ao silêncio (pp. 15-46). Brasília: LetrasLivres; EdUnB, 2009. 
CARMO, H.; FERREIRA, M. Metodologia da investigação: guia para autoaprendizagem. Lisboa: Universidade Aberta, 2009.

COSTA, C. G.; OLIVEIRA, J.M.; NOGUEIRA, C. Os discursos das pessoas LGBT. In: OLIVEIRA, J. M.; Nogueira, C. (Org.). Estudo sobre a discriminação em função da orientação sexual e da identidade de género. Lisboa: Comissão para a Cidadania e Igualdade de Género, 2010, p. 211-242.

DIÉZ GUTIÉRREZ, E.(cord.) La diferencia sexual en el análisis de los videojuegos. Madrid: CIDE/Instituto de la Mujer, 2004.

DOMÍNGUEZ, B. G. de G. Glee: el êxito de la diferencia. Sesión no numerada: Revista de letras y ficción audiovisual. Espanha, nº 1, año 2011, pp. 47-59.

FOLHAS, D.; PESSOA, T.; TEIXEIRA, F. Sexualidade e género na série televisiva Morangos com Açúcar. In Teixeira et al (Orgs.). Sexualidade e educação sexual: políticas educativas, investigação e práticas. Braga: Edições CIEd, 2010, p. 308312 .

JUNQUEIRA, R. D. Homofobia nas escolas: um problema de todos. In: (Org). Problematizações sobre a homofobia nas escolas. Brasília: MEC/UNESCO, 2009a, p. 13-51.

Políticas de educação para a diversidade sexual: escola como lugar de direitos. In: LIONÇO, T.; DINIZ, D. (Orgs). Homofobia \& Educação: um desafio ao silêncio. Brasília: Letras Livres; EdUnB, 2009b, p. 161-193.

LEAL, I. Parentalidades. Questões de género e orientação sexual. In: CASCAIS, A. F. (org.). Indisciplinar a teoria. Estudos gays, lésbicos e queer. s.I.: Fenda, 2004, p. 215-240.

LOURO, G. O corpo educado: pedagogias da sexualidade ( $2^{\mathrm{a}}$ ed.). Belo Horizonte: Autêntica, 2000a.

Currículo, género e sexualidade. Porto: Porto Editora, 2000b.

Heteronormatividade e homofobia. In Junqueira,R.D. (org). Diversidade sexual na educação: problematizações sobre a homofobia nas escolas. Brasília: MEC/UNESCO, 2009, p. 86-93.

MONTEZUMA, M. Orientação sexual, homofobia e educação. Trabalho de projeto [Mestrado em Educação para a Saúde]. Coimbra: ESTeSC/ESEC, 2012.

NOGUEIRA, C.; OLIVEIRA, J.M. Um olhar da psicologia feminista crítica sobre os direitos humanos de pessoas LGBT. In Oliveira, J. M. \& Nogueira, C. (Org.). Estudo sobre a discriminação em função da orientação sexual e da identidade de génerO. Lisboa: Comissão para a Cidadania e Igualdade de Género, 2010, p. 9-17. 
OLIVEIRA, J.M.; PEREIRA, M.; COSTA, C.; NOGUEIRA, C. Pessoas LGBT identidades e discriminação. In: OLIVEIRA, J. M.; NOGUEIRA, C. (Org.). Estudo sobre a discriminação em função da orientação sexual e da identidade de género. Lisboa: Comissão para a Cidadania e Igualdade de Género, 2010, p. 149-210.

PEREIRA, H.; LEAL, I. (). A homofobia internalizada e os comportamentos para a saúde numa amostra de homens homossexuais. In: CASCAIS, António Fernando (org.). Indisciplinar a Teoria. Estudos Gays, Lésbicos e Queer. s.I: Fenda, 2004, p. 245-260.

RIOS, R. Homofobia na Perspectiva dos Direitos Humanos e no Contexto dos estudos sobre preconceito e discriminação. In: JUNQUEIRA, R. D. (Org.) Diversidade Sexual na Educação: problematizações sobre a homofobia nas escolas. Brasília: MEC/UNESCO, 2009, p. 53-83.

RODRIGUES, L.; NOGUEIRA, C.; OLIVEIRA, J.M. Violência em casais LGBT Estudo preliminar. In:OLIVEIRA, J. M.; NOGUEIRA, C. (Org.). Estudo sobre a discriminação em função da orientação sexual e da identidade de género. Lisboa: Comissão para a Cidadania e Igualdade de Género, 2010, p. 243 - 266.

SOUZA FILHO, A. Teorias sobre a Gênese da Homossexualidade: ideologia, preconceito e fraude. In Junqueira, R. D. (Org.) Diversidade sexual na educação: problematizações sobre a homofobia nas escolas. Brasília: MEC/UNESCO, 2009, p. 95-124.

TEIXEIRA, F. Educação em Sexualidade e Formação de Professores(as). In: TEIXEIRA, F. et al (Orgs.). Sexualidade e educação sexual: políticas educativas, investigação e práticas. Braga: Edições CIEd, 2010, p. 315-319.

VALE DE ALMEIDA, M. Teoria queer e a contestação da categoria "género". In: CASCAIS, A. F. (org.). Indisciplinar a teoria. Estudos gays, lésbicos e queer (pp. 9198). s.I: Fenda, 2004.

WEEKS, J. O corpo e a sexualidade. In: LOURO, G. (Org.). O corpo educado: pedagogias da sexualidade. Belo Horizonte: Autêntica, 2000, p. 35-82.

\footnotetext{
Este trabalho é financiado por Fundos Nacionais através da FCT - Fundação para a Ciência e a Tecnologia, I.P., no âmbito do projeto UID/CED/00194/2019.
}

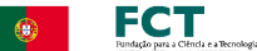

